\title{
Assessment of the Environmental Impact of Road Infrastructure in Countries: A Study of the Namibia Scenario
}

\author{
Victor Uzoma Nwagbara1, William Azuka Iyama² \\ ${ }^{1}$ Faculty of Engineering, Namibia University of Science and Technology, Windhoek, Namibia \\ ${ }^{2}$ Department of General Studies, Rivers State College of Health Science and Management Technology, \\ Port Harcourt, Nigeria \\ Email: uvictor@nust.na, iyamawilliamazuka@rschst.edu.ng
}

How to cite this paper: Nwagbara, V. U., \& Iyama, W. A. (2019). Assessment of the Environmental Impact of Road Infrastructure in Countries: A Study of the Namibia Scenario. Journal of Geoscience and Environment Protection, 7, 86-101.

https://doi.org/10.4236/gep.2019.712006

Received: October 5, 2019

Accepted: December 14, 2019

Published: December 17, 2019

Copyright $\odot 2019$ by author(s) and Scientific Research Publishing Inc. This work is licensed under the Creative Commons Attribution International License (CC BY 4.0). http://creativecommons.org/licenses/by/4.0/

\section{Open Access}

\begin{abstract}
The assessment of the impact of road infrastructure in the developing countries using the Namibian case scenario was done based on the contemporary challenges of road use. This study employed a qualitative technique using a sample size of thirty (30) selected by the simple random sampling technique. The use of charts, tables and frequencies were done to explain certain trends in the study. A well-structured, valid and reliable questionnaire instrument was designed for the study based on the following research questions; what are the impacts of road transport on the Namibian environment and what are the possible measures that may be used to reduce environmental impact of road transport on the Namibian environment? Twenty five respondents (83\%) agreed that road transfer has drastically improved development and 26 (87\%) respondents also accepted that it can improve Namibian economy. Similarly, it has also improved communication and technology greatly according to $27(90 \%)$ respondents. To add more credence to the impact of road transport on the economy, all the $30(100 \%)$ of the respondents agreed that road transport aids mobility within Namibia while 27 (90\%) respondents supported the opinion that road transport aids in job search, 3 (10\%) disagreed. The result shows that car owners service are potential threats which can affect pollution levels as was supported by $97 \%$ to cause environmental pollution as well as $100 \%$ when combined with energy consumption. Similarly, all the respondents indicated the potential of increased accident rate from poor road safety. Felling of trees poses great danger (97\% response) due to the degradation of the environment. Most respondents (77\% and 83\%) agreed that road transport can lead to land encroachment and loss of aesthetic and farming. This research has shown that eventually death rate may
\end{abstract}


increase from mere ill-health to from the degraded ecosystem, 24 respondents (80\%). So many policies to protect the environment but the practical measures are to encourage impact assessment studies for road projects, land use control and human safety precautions on road use.

\section{Keywords}

Infrastructure, Impact, Environment, Road Transportation, Assessment, Developing, Economy

\section{Introduction}

Global technology and scientific innovation in transportation system has resulted in improvement of global economy and caused environmental degradation. Transport plays an important part in economic growth and globalisation, but most times cause air pollution and use large amounts of land. While it is heavily subsidized by governments, good planning of transport is essential to make traffic flow, and restrain urban sprawl. Road infrastructure therefore is a part of structure; material or economic base of a society or an organization. It is a basic structure that fosters the good performance of cities', states' or countries' essential services. In this sense, for a country to have a good logistics infrastructural system in the different modes of transportation, constant investment from both public and private sectors are needed.

Therefore, road transportation is the act of moving passengers or goods from one location to another. Modes of transport include air, rail, road, water, cable, pipeline and space. The field can be divided into infrastructure, vehicles, and operations. Road transport is important since it enables trade between peoples, which in turn establishes civilizations (Ovubude, 2005). Transport infrastructure consists of the fixed installations necessary for transport, and may be roads, railways, airways, waterways, canals and pipelines, and terminals such as airports, railway stations, bus stations, warehouses, trucking terminals, refuelling depots (including fuelling docks and fuel stations), and seaports. Terminals may be used both for interchange of passengers and cargo and for maintenance (Meik et al., 2002). In the transport industry, operations and ownership of infrastructure can be either public or private, depending on the country and mode (Starkey et al., 2012).

Passenger transport may be public, where operators provide scheduled services, or private. Freight transport has become focused on containerization, although bulk transport is used for large volumes of durable items. Transport plays an important part in economic growth and globalization, but most types cause air pollution and use large amounts of land. While it is heavily subsidized by governments, good planning of transport is essential to make traffic flow and restrain urban sprawl (Starkey et al., 2012). 
The study will pay more attention to road transportation. Since 1990 after independence, Namibia's road transportation infrastructure has enjoyed the largest outlay of central government investment compared with other modes and remains the preferred option for door to door linkage. Until recently, the policy initiative on road infrastructure development, funding, maintenance and even operations has been the sole responsibility of the various systems of government (Law Library of Congress, 2014).

According to the Namibia's Greenhouse Gas Inventory for the Year 2000, greenhouse gas levels within Namibia have rapidly increased, in comparison with the greenhouse gas levels of the year 1994. The increase of the level of greenhouse gases is caused in part by the increase in road transportation within the country (Ministry of Environmental\& Tourism, 2008). This study joins the debate by investigating the impact of road transportation on the Namibian environment. The environmental impacts of road transportation have amplified due to increasing transport volumes and the increasing use of road transportation. According to Robinson, 2011 \& Groth, (2012) transport volumes as well as the proportions of the road sector is continuously rising, this intensifies the environmental impacts. Road transportation is especially guilty of this as it contaminates the environment with the release of exhaust emissions. Within the assessment factors such as costs caused per transport are calculated. The analyses include aspects like capacity utilization, the use of environmentally friendly tires and eco-friendly driving styles. These factors influence the fuel consumption and thus also the final production of exhaust emissions (Meik, Jeo, Mendelsohn, Jenks, 2009). The different modes of transport include human-powered, animal-powered and road transports (Meik et al., 2009; Sharpley, 2012; Robinson, 2011 \& Groth, 2012).

Road transportation is a very popular mode of transport and yields many benefits for the economy as well as the citizens of Namibia. Not only does it allow social integration, but it enhances economic efficiency, as it decreases costs and prices and enhances trade and employment activities. Road transport in Namibia has social, economic, political and environmental and energy roles. However; road transportation also poses a great threat to the environment of Namibia. Not only does the natural habitat of certain plants and animals get destroyed due to the building of road infrastructure, but the road transportation also increases the greenhouse gases and pollutes the air. Road transportation is especially guilty of contaminating the environment with the release of exhaust emissions which has negative environmental impact. Road transportation, however, consumes a lot of resources, such as the land on which roads are built, deforestation which has negative impact on the environment and also much time is engulfed in building, maintaining and operating the road transportation system. Impacts of transport on the ecosystem include direct, indirect and cumulative impacts (Petzman, 2009). But Sharpley (2012), explained that the most important impacts of road transport on the environment relate to climate change, air quality, noise, water quality, soil quality, biodiversity and land take (invasion). 
This study therefore analysed the environmental and social impact of road transportation on the environment of Namibia, with the aim of finding possible solutions.

\section{Methodology}

\subsection{Research Design}

The qualitative method was adopted which has been taken as a loosely defined category of research design which is field focused and deals with subjective data in descriptive form like note, recording or other descriptions (Bless \& Higson-Smith, 2000). It is sometimes referred to as interpretative, naturalistic and descriptive research, involving small groups of data. Qualitative research according to Creswell (2014) is also hypothetical, particularistic, impersonal, experimental and stable. It is the outsider's perspective of the problem and it is unbiased. The researcher proposed that this method was good to collect the best results, because the researcher manipulated them efficiently and effectively.

\subsection{Sampling and Population of the Study}

According to Kruger et al. (2001), the concept of sampling is one of the most important in the total research endeavour as it is imperative that a researcher has to understand clearly before selecting, sampling, conducting the pilot study and main research. "Sampling refers to elements of the population considered for actual inclusion in the study" (Creswell, 2008). The sample size was selected by a simple random sampling process proportional to population. Males and Females were selected in alternation in successive sampling process, so that in the end, the sample consisted of 15 females and 15 males. The respondents will be estimated statistically using percentage.

In the case of this study the considered population were some employees of Ministry of Environment and Tourism, some employees of road transport companies and rod users in Windhoek. This was a single case study in which the ideal way to investigate the impact of road transportation on the Namibian environment. The study was participated by only petite portion of the population of road users and employees of Ministry of environment and employees of some selected road transport companies involving thirty (30) participants from the total population.

\subsection{Data Collection Instrument}

A questionnaire was designed to capture data from the participants. The structured questionnaires consisted of closed ended questions in order to capture as much data as possible for analysis. Questions included in the questionnaire were designed in such a way that they were short, clear and precise. This was to ensure that the respondents have a common understanding of the questions asked and as well make the questions short and interesting. In addition to the formal questionnaires, interviews were also conducted. An interview is "a data-collec- 
tion encounter in which one person (an interviewer) ask questions on another (a respondent)" (Kruger et al., 2001). It is "a mainstay of field research used both by participant, observers and by researchers who make no pretense of being a part of what is being studied" (Kruger et al. 2001). Interviews can be divided into three main categories, namely: structured, semi-structured, and unstructured. This research study will achieve the following objectives; analyse the impacts of road transport on the Namibian environment, evaluate the policies in place that protect the environment towards road transport and recommend the possible measures that may be used to reduce the environmental impact of road transport on Namibian environment.

This study is driven by the following research questions:

1) What are the impacts of road transport on the Namibian environment?

2) What are the policies in place that protect the environment towards road transport?

3) What are the possible measures that may be used to reduce the environmental impact of road transport on Namibian environment?

\subsection{Method of Data Analysis}

Interpretation was taken from the results and analysed and making inferences pertinent to the researcher relationship with studies and drawing conclusion. The broader meaning of research data was sought. In this method the researcher compared the results and the inferences drawn from the analysis. Structured interview by the researcher helped in making conclusion about the results. The use of charts and simple tables were employed to analyse and interpret the data. The well-structured questionnaire was given to some other experts to assess in order to confirm its coherence and validity. To test for its reliability, the test-retest method was adopted using the Pearson's Product Moment Correlation Coefficient to obtain the coefficient of variation as 0.78 which indicates its reliability (reliable if coefficient of reliability is $\geq 0.5$ ). Reliability is the degree of consistency between two measures of the same thing (Welman \& Kruger, 2001). Reliability refers also to the degree to which the independent administration of instrument yielded a similar or the same result under comparable situation.

\section{Results}

The findings on the demography and questionnaire about the impact of road infrastructure on the Namibia environment were illustrated by making use of graphical and descriptive statistics. The study was carried out among the employees of Ministry of environment and tourism employees, employees of some road transport companies and road users in Windhoek. Though most of the respondents have little or no knowledge about environmental impact of road infrastructure, the research had to explain this to them as the researcher interviewed some of the respondents to get vivid information from them.

Table 1 shows that 2 respondents indicated that they had master's degree, 5 respondents indicated they had bachelor's degree, 10 respondents indicated that 
they had diploma while the remaining 13 respondents are grade 12 holders representing the major educational levels. Similarly, Table 1 also shows that 13 respondents were between the ages of $21-29$ years, while 10 respondents were between the ages of 30 - 39 years and the remaining 7 respondents were more than the ages of 40 years representing all the major age groups.

Demographical details include the gender of the respondents, educational levels and age category. Such information is very critical as it may then provide explanation to responses to some objectives. These are two examples demonstrating the importance of the demographical details of the respondents. From Figure 1 it shows that males and females were equally represented (15 males and 15 females).

From Figure 2, 25 (83\%) respondents indicated "Yes" that road transportation has drastically improved development while the remaining 5 (17\%) respondents indicated "NO". Road transportation improves economy of Namibia in so many ways.

From Figure 3, 26 (87\%) respondents indicated "Yes" that road transportation improves economy of Namibia, while the remaining 4 (13\%) respondents indicated "NO". Road transportation has improved communication and technology.

Table 1. Educational qualification and age range of respondents.

\begin{tabular}{cccc}
\hline Educational Level & Frequency & Age & Frequency \\
\hline Masters & 2 & $21-29$ & 13 \\
Masters & 5 & $30-39$ & 10 \\
Diploma & 10 & $>40$ & 7 \\
Grade 12 & 12 & 12 & \\
\hline
\end{tabular}

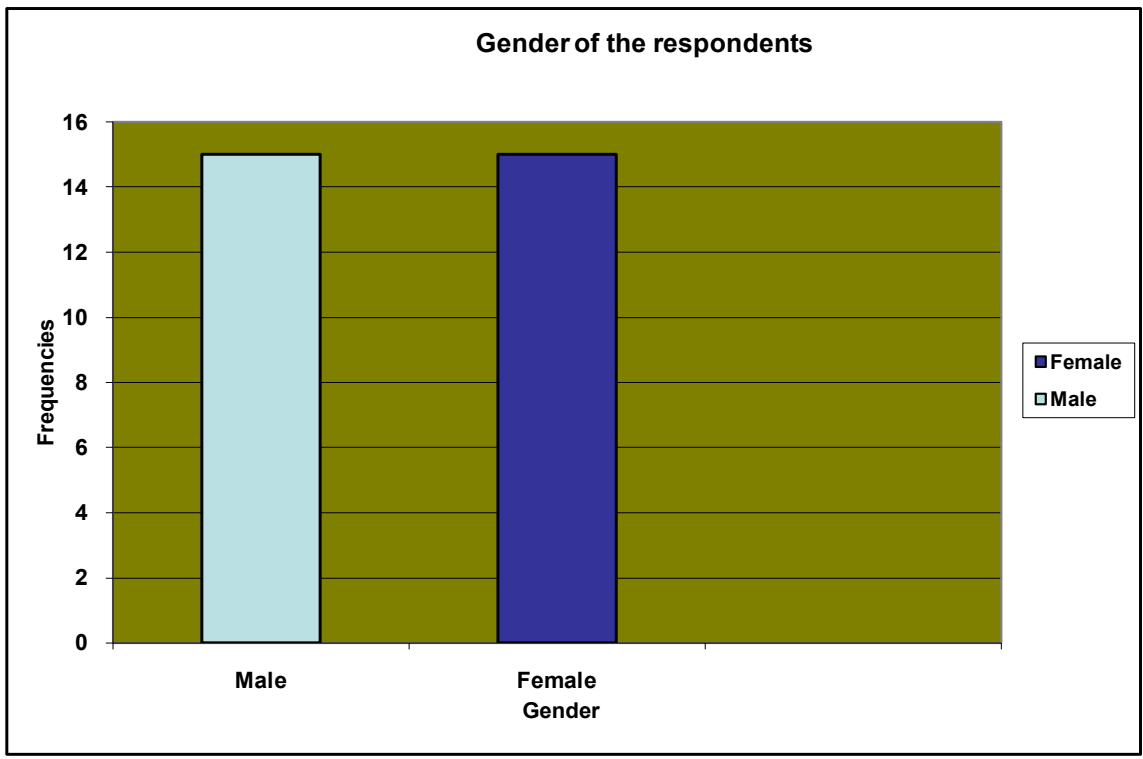

Figure 1. Demography of respondents. 


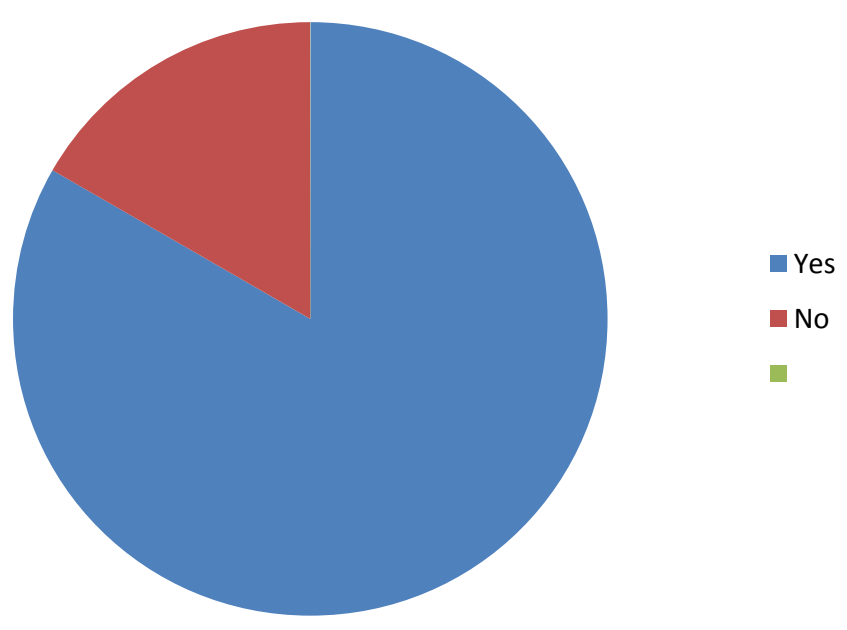

Figure 2. Role of road transportation at the development of namibia.

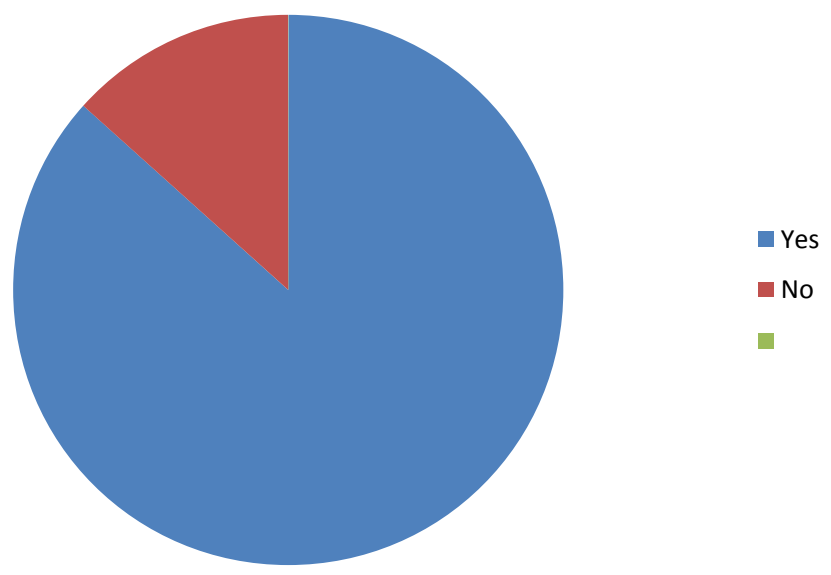

Figure 3. Road transport impact on economy.

Figure 4 showed that 27 (90\%) respondents indicated "Yes" that road transportation has improved communication and technology greatly, while the remaining 3 (10\%) respondents indicated "NO".

From Figure 5, all the respondents (100\%) indicated "Yes" that road transportation aids movement within Namibia.

From Figure 6, 27 (90\%) respondents indicated "Yes" that road transportation helps in job search while the remaining $3(10 \%)$ respondents indicated "NO".

From Table 2, 5 (17\%) respondents indicated that they service their cars "once", 10 (33\%) respondents indicated that they service their cars at least 2 or 3 and 4 to 5 times yearly. While the remaining $5(17 \%)$ respondents indicated that they service their cars 6 to 7 times yearly.

From Figure 7, 29 (97\%) respondents indicated "Yes" that road transportation technologies cause pollution to the environment, while the remaining 1 (3\%) respondent indicated "NO".

Figure 8 indicates that all the $30(100 \%)$ respondents agreed that road transportation and the energy consumption causes pollution. 


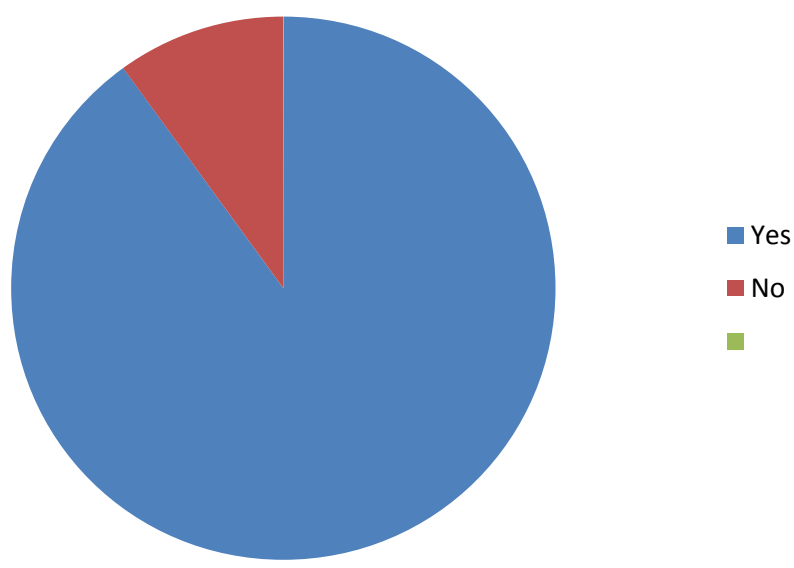

Figure 4. Impact of road transport on communication and technology.

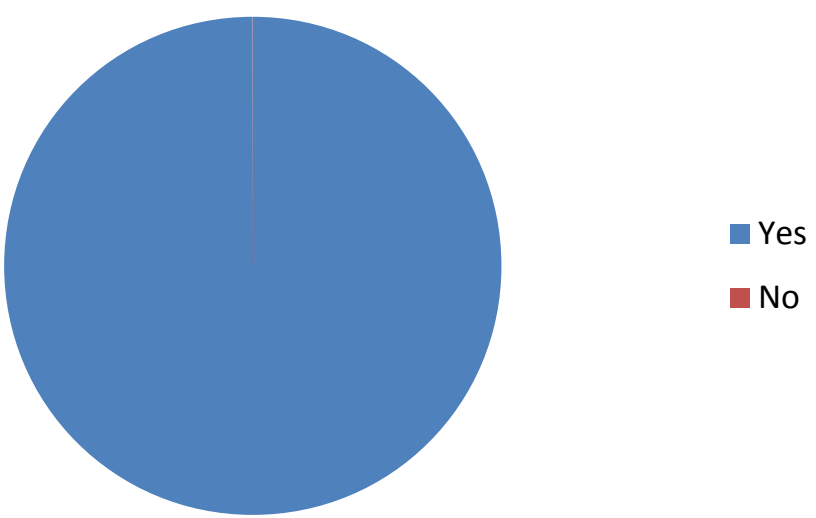

Figure 5. Road transportation on mobility within namibia.

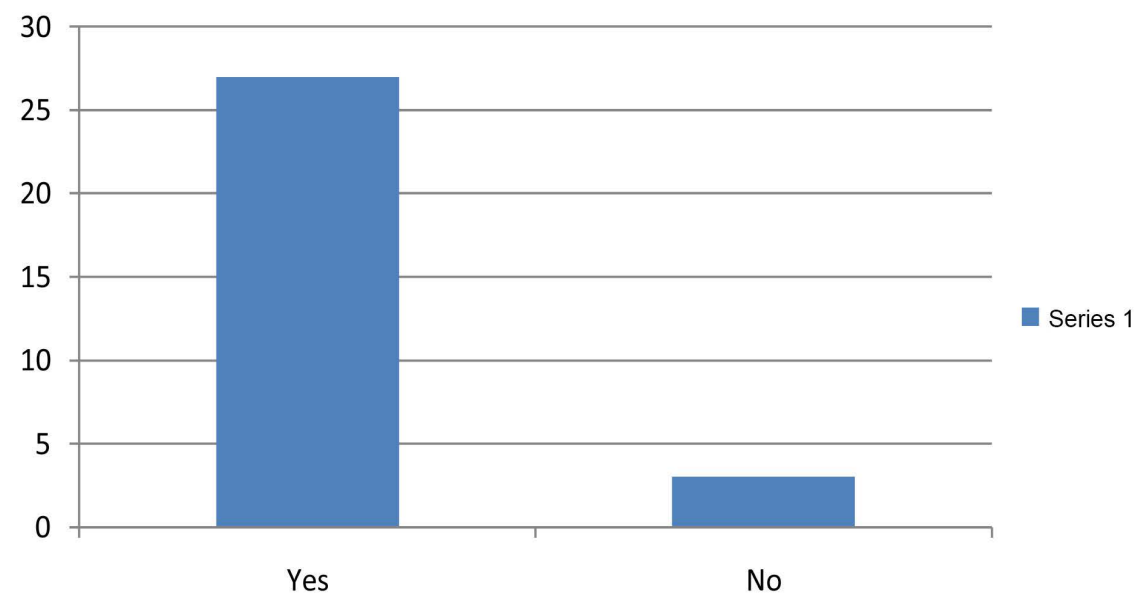

Figure 6. Impact of road transport on job search.

All the respondents indicated "Yes" that road accident can increase accident and poor road safety (Figure 9 ).

From Figure 10, twenty seven (90\%) respondents indicated "sometimes" that felling of tees leads to degradation of the environment, while the remaining 3 (10\%) respondents indicated "NO". 
Table 2. Number of times respondents service their cars.

\begin{tabular}{cc}
\hline Frequency & Occurrence \\
\hline Once & $5(17 \%)$ \\
Not at all & 0 \\
$2-3$ times & $10(33 \%)$ \\
$4-5$ times & $10(33 \%)$ \\
$6-7$ times & $5(17)$ \\
\hline
\end{tabular}

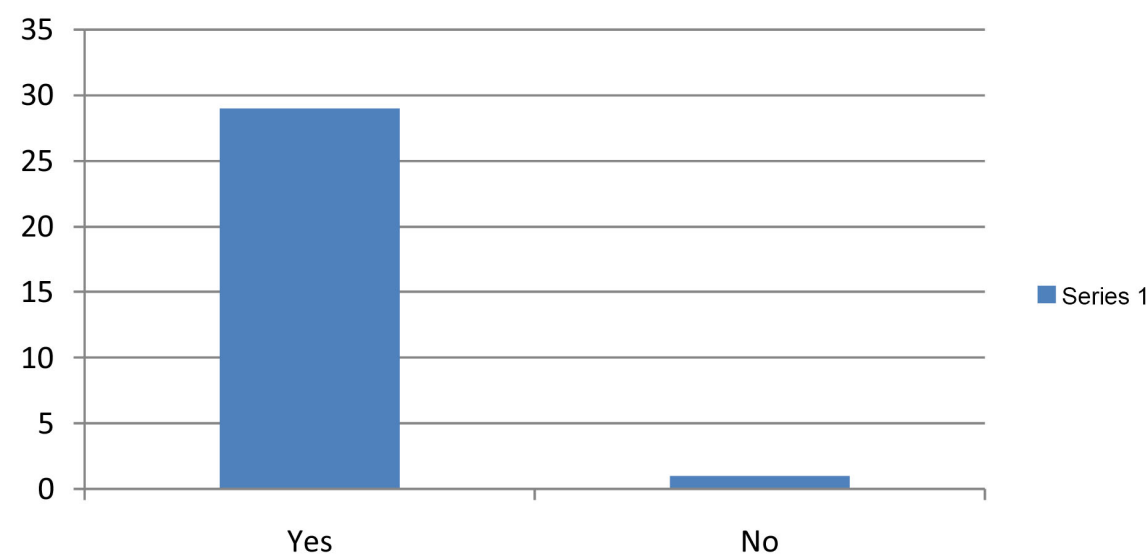

Figure 7. Impact of road transport on environmental pollution.

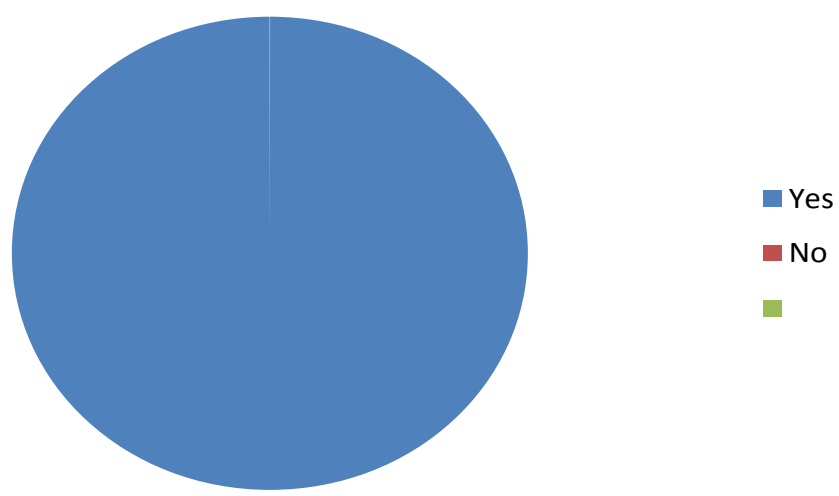

Figure 8. Road transport, energy consumption and pollution.

From Figure 11, 23 (77\%) respondents indicated "sometimes" that road transportation lead to land use and encroachment which inhibit adequate land for housing, while the remaining 7 (23\%) respondents indicated "NO".

From Figure 12, 25 (83\%) respondents indicated "Sometimes" that road transportation leads to loss of aesthetics and farming, 3 (10\%) respondents indicated "Not at all" while the remaining 2 (7\%) respondents indicated "always".

From the Figure 13, 24 (80\%) respondents indicated "Sometimes", that pollution caused by road transportation can lead to ill-health of residents living within the environment of the road, while 3 (10\%) respondents each indicated "Always" and "Not at all" respectively. 


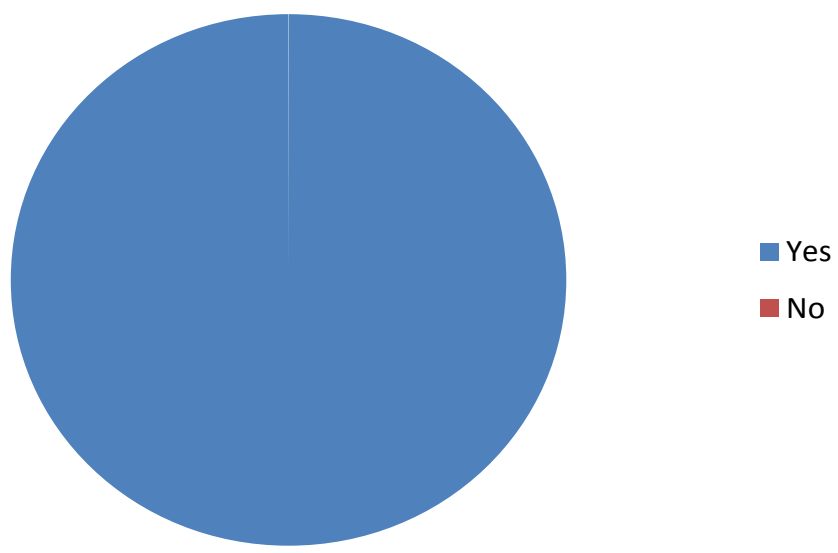

Figure 9. Road transportation impact on road safety.

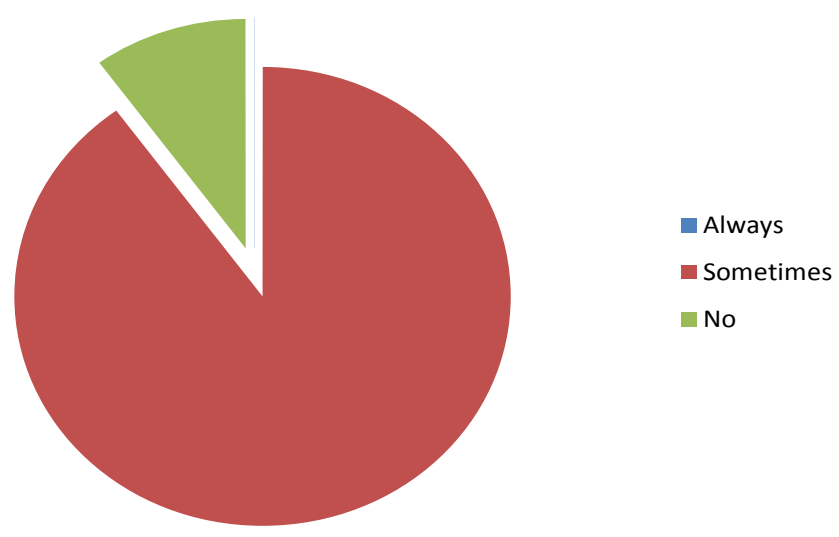

Figure 10. Road transport and environmental deforestation.

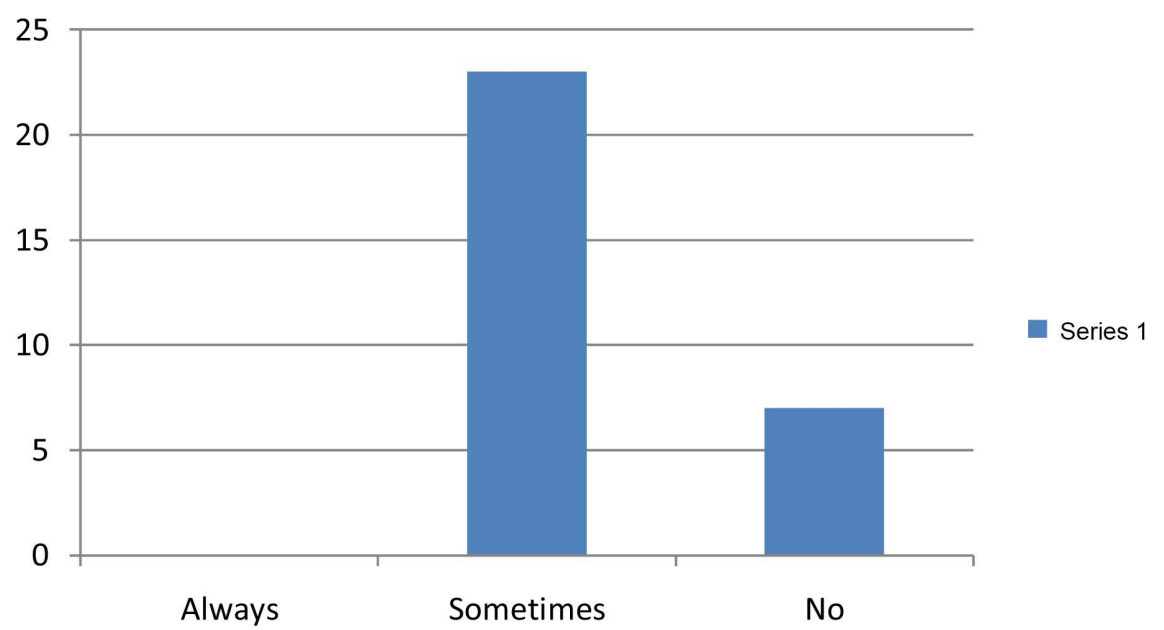

Figure 11. Road transport and land use.

\section{Discussion of Findings}

From Table 2, the analysis it shows that road transportation has really created impact especially on the area of development thereby generating revenue in the area of transportation to the government and individuals. In some aspect also, 


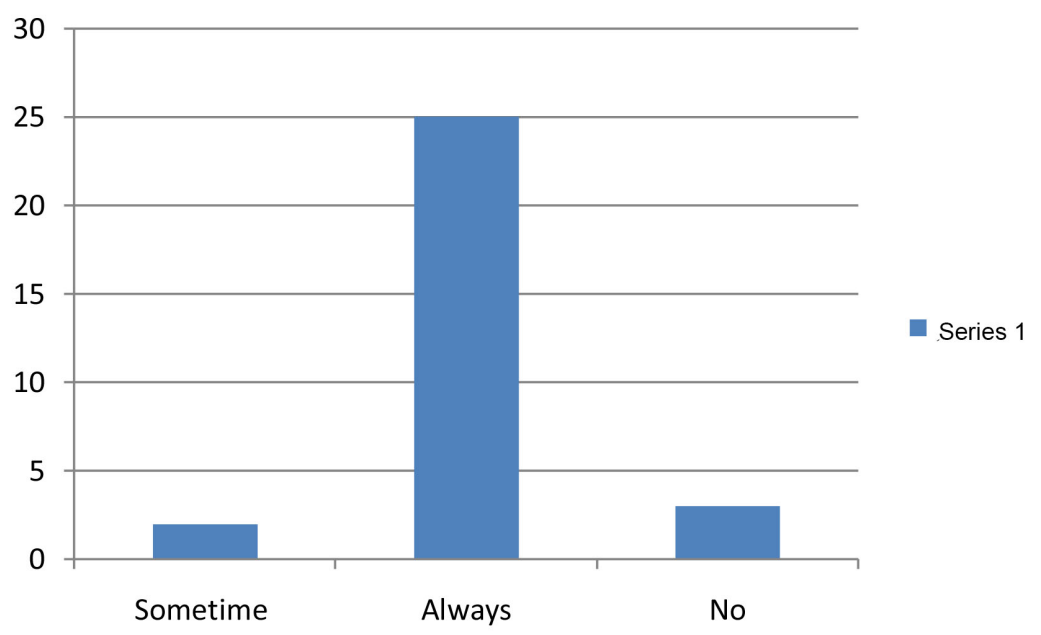

Figure 12. Impact of road transport on aesthetics.

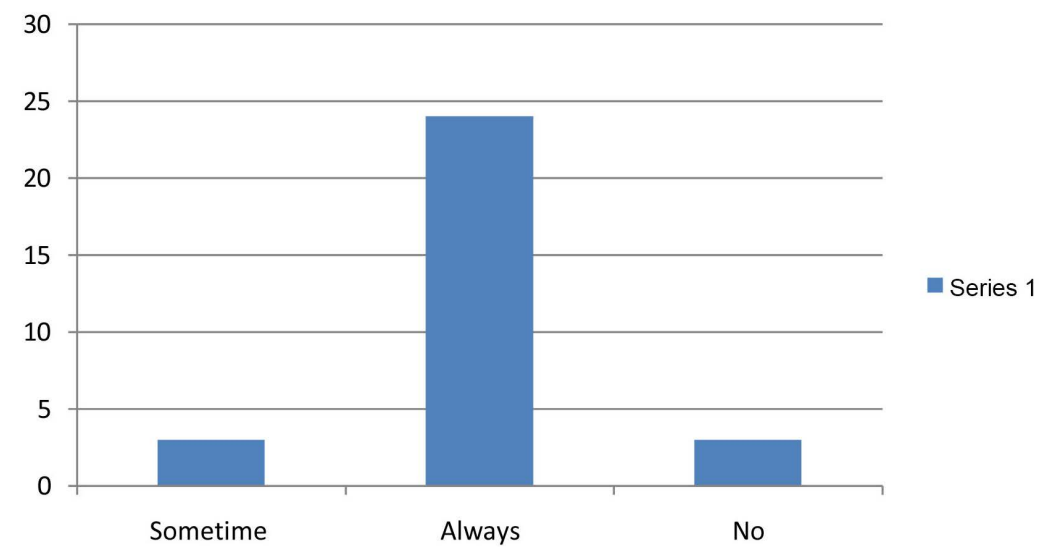

Figure 13. Road transport impact and health challenge.

road transportation has led to improve quality of lives because many under-developed communities are experiencing rodal routes thereby facilitating and easing burden of movement from one place to another. The current developments of roads promote growing concern for sustainable and eco-friendly transportation globally (Condurat, Nicuta, \& Andrei, 2017). Many rural areas are now far becoming township because of road transportation that passed through those areas. From Figure 3, the analysis shows that road infrastructure generate revenue for the government and individual. Transporters generates generate as they increase more automobiles on the road and this also create employment for unemployed because they can act as drivers or co-drivers which invariably create employment and generate more revenues for transport owners. The importance of specific transport activities and infrastructure can thus be assessed for each sector of the economy (Arasan \& Koshy, 2013). Government of Namibia also have buses that ply different routes especially in Windhoek, transporting people from one part of the city to another. This generates revenue for the government in maintaining roads. 
Figure 4 shows that road transportation has eased communication process among people either via sending of mail through courier services, post office (Nampost). This has undoubtedly had a very considerable effect in the level of understanding of different groups and the mutual respect of one socio-economic group for another (Ministry of Environment and Tourism, 2014). In developing countries, the lack of road transportation infrastructures and regulatory impediments are jointly impacting economic development by conferring higher transport costs, but also delays rendering supply chain management unreliable (Ritz \& Clarke, 2010). Technology has been improved through road transportation because places that are not accessible by people are made accessible because people can travel long distance without distress, communicate effectively and also transport some communication gadgets from one place to another. The world has been reduced into a global village as a result of development in transportation technology (Mendelsohn, Jarvis, Robert, \& Robertson, 2009). There is therefore cause for concern while considering the road transport infrastructure base in Namibia today which compares unfavorably with those of several African nations both in terms of quality and service coverage. In particular, the rural areas, where the bulk of the population resides, are largely deprived of basic pieces of road transport infrastructure (Ritz \& Clarke, 2010).

In Figure 5 specifically, movement from one place to another will be limited if there was limited road transport in the country. So road transportation has invariably ease movement and made life easier in moving from places to places. Similarly, Figure 6 shows that people can always take road transport to wherever they wish to search for employment because of its affordability. Providing this mobility which is transportation provides an industry that offers services to its customers, employs people and pays wages, invests capital and generates income (FAO, 2010). Road transportation is the affordable among all different modes of transportation. Despite the affordability, it is also accessible and can access any routes especially for employment purposes.

Table 2 also shows that most of the respondents service their cars averagely twice yearly. The number of times that a car is serviced has an impact on an environment especially on the area of pollution. If a car is serviced regularly, pollution will be minimized. All hazardous particles emitted from the exhaust pipe of the cars may be minimized and this will invariably reduce harmful gases that are dangerous to human health to be reduced too. Gichaga (2017) recommended geometric design of road, driver training and behaviour, vehicle maintenance and utilization of road safety parks.

Figure 7 shows that road transportation may facilitate movement but it has also detrimental effect to the environment. In the area of grading, pollution is cause because of the dust that the grader will disperse. In the area of road construction, deforestation will be caused which leads to desertification and global warming as was agreed by Sharpley (2012) on the effect on biodiversity and extinction potentials. So invariably, road transportation technologies have environmental effect to the environment. Research has shown the transport sector 
alone contributes about $19.2 \%$ of carbon emission and has a potential to reduce emission by 4\% (Abraham, Ganesh, Kumar, \& Ducqd, 2012). Similarly, anthropogenic activities such as deforestation and burning of fossil fuels increases greenhouse gas emissions (Abraham et al., 2012). Research has also shown that there is exponential increase in the emission of greenhouse and fuel consumption according to Condurat et al. (2017) which promotes pollution. Similarly in Figure 8, the respondents agreed that road transportation consumes lots of energy which indirectly causes pollution. Increasing noise levels have a negative impact on the urban environment reflected in falling land values and loss of productive land uses (Sharpley, 2012). From all indication it shows that vehicles which ply on the roads use energy which is derived from the petrol and diesel which contain some hazardous substances that are dangerous to human health and the environment. Rodrigue (2012) mention transportation as one of the behavioural factors that contribute to air pollution, notably in urban areas.

These hazardous substances include sulphur dioxide, nitrogen dioxide, carbon monoxide, arsenic and all these substances can cause respiratory disorder, cancer, or they can suffocate someone to death. The physical and chemical properties of particulates are associated with health risks such as respiratory problems, skin irritations, eyes inflammations, blood clotting and various types of allergies (Sharpley, 2012).

Based on some facts recorded by motor vehicle accident (MVA), most deaths are caused by road accident as shown in Figure 9. Many people have turned road as a suicidal track instead of transportation track. They have turned road as an express to death, either because they are drunk, frustration or even suicidal. So inferno caused on the road transportation cannot be quantified by the benefits it brings to the society. People's lives are endangered, and many have gone because of mistakes of poor road safety. The probability of being killed by road accident is a function of where the individual resides (Wegman, 2017). Nonhuman factors to traffic accidents involve mostly motorbikes in Indonesia but the major remedial actions are development of public transportation, improvement of road ratio and traffic management measures (Soehodho, 2016). Felling of trees to construct road leads to deforestation which is the main cause of desertification and global warming. This means that the transport sector must be decarbonized to maintain the safety threshold of a $2^{\circ} \mathrm{C}$ increase in average temperature (Santos, 2017). This is militated against by lack of global legally binding agreement and the high relative cost of clean vehicle and energy technology (Santos, 2017). Some of these gases, particularly nitrous oxide, also participate in depleting the stratospheric ozone $\left(\mathrm{O}_{3}\right)$ layer which naturally screens the earth's surface from ultraviolet radiation (Sharpley, 2012). When these two conditions prevail, they destabilise the environment thereby having negative impact on the environment which is also illustrated in Figure 10.

Chemicals used for the preservation of railroad ties may enter into the soil and so hazardous materials and heavy metals have been found in areas contiguous to railroads, ports and airports (Sharpley, 2012). Figure 11 indicates that many 
lands that could have been used for housing and farming are practically under used because they are diverted to be used for the construction of roads. This has really affected housing thereby increasing rental and prices of houses. When this occurs people tend to encroach into use of land to build informal settlements and squatter camps which invariably make this city unplanned. This agrees with the works of Sharpley (2012) on the negative impact on urban environment reflected in falling land values and loss of productive land uses (Sharpley, 2012). Transportation also became an important dimension of the concept of sustainability, which is expected to become the prime focus of transport activities in the coming decades, ranging from vehicle emissions to green supply chain management practices (Starkey, Ellis, Hine, \& Ternell, 2012). These invariably affect the environment. From all indications it shows that most land cannot be used for farming because of the loss of nutrients. Most of them have been affected by chemicals used in construction of the road like bitumen which erodes nitrogen from ground soil when come in contact with it. So loss of aesthetics for farming on land can lead to famine and this invariably has negative impact on the environment which is illustrated in Figure 12. However, roads and highways can produce complex negative impacts. The impacts of improvement, rehabilitation and maintenance projects, although usually more limited, can still be significant, not only on natural resources and systems but also on the social and cultural environment (Ashley, 2010). Similarly, significant decrease was observed at barren and agricultural land classes (Demirel, Sertel, Kaya, \& Seker, 2008).

From all indications as shown in Figure 13, dangerous gases emitted by vehicles plying the road can have negative health issues with people living around the environment, and this health issues might lead to health complications because of excess inhalation. This was not the case as absolute levels of air pollutants emissions have considerably dropped in developed countries such as the United States (Rodrigue, 2012). The issue of transportation and the environment works hand in hand in nature since transportation conveys substantial socioeconomic benefits, but at the same time transportation is impacting environmental systems (Petzman, 2009). Road transport also carries an important social and environmental load, which cannot be neglected (Minh, 2012). These impacts fall within three categories as corroborated by Petzman (2009) to include direct, indirect and cumulative. Some major negative impacts of transportation on the environment can include degradation of air quality, greenhouse gas emission, increased threat of global climate change, degradation of water resources, noise and habitat loss and fragmentation (Demirel, Sertel, Kaya, \& Seker, 2008).

\section{Conclusion}

The different roles and impacts of transportation in our society have been highlighted. The negative impacts such as pollution, noise, and loss of aesthetics, consumption of energy, loss of land, safety and accidents resulting from the use of road transportation or another have been discussed in detail. Considering 
these negative impacts one may be tempted to write off road transportation as highly detrimental to the development and progress of any nation. It is however evident from the positive roles played by road transportation as discussed in this paper that transportation is indispensable and relevant in the development of a society. This paper has revealed the impact of the expansion of road, in some major commercial areas of Namibia (especially the Northern parts). The loss of customers due to the demolition of business premises, accompanied by inaccessible roads to new make-shift shops had resulted into reduction in profit and meagre income for some people residing where new road constructions are done. The study recommends the provision of accessible and affordable shopping complexes for the traders and speedy completion of the road project to reduce the hindrance of customers in reaching the business area which affects the economy of the informal workers. There is the need to take into cognisance the informal sector and their space requirement while planning the city. Findings by Ovubude (200) have shown that the movement of passengers and freight in rural areas of Nigeria are comparatively smaller than those of intra-urban movement.

However, more needs to be done to reduce the emission of particulates and oxides of nitrogen. As with other pollutants, the imposition of increasingly demanding targets is the single most effective way of stimulating improvements in the vehicle fleet. Governments therefore need to impose more demanding air quality standards, and to require action to achieve these standards first in those areas where larger numbers of people are exposed. Land consumption for transport infrastructure can adversely affect biodiversity and contribute to urban sprawl, hence there is need for interaction between land use and transport planning which will help to steer transport infrastructure away from protected areas enabling infrastructure, or to share the risk in pilot applications.

\section{Conflicts of Interest}

The authors declare no conflicts of interest regarding the publication of this paper.

\section{References}

Abraham, S., Ganesh, K., Kumar, A. S., \& Ducqd, Y. (2012). Impact on Climate Change Due to Transportation Sector-Research Perspective. Procedia Engineering, 38, 38693879. https://doi.org/10.1016/j.proeng.2012.06.445

Bless, C., \& Higson-Smith, C. (2000). Fundamentals of Social Research Methods: An African Perspective. Cape Town: Juta and Company.

Condurat, M., Nicuta, A. M., \& Andrei, R. (2017). Environmental Impact of Road Transport Traffic: A Case Study for Country of Iasi Road Network. Procedia Engineering, 181, 123-130. https://doi.org/10.1016/j.proeng.2017.02.379

Creswell, J. (2008). Qualitative Inquiry and Research Design: Choosing among Five Traditions. Thousand Oaks, CA: Sage.

Demirel, H., Sertel, E., Kaya, S., \& Setker, D. Z. (2008). Exploring Impacts of Road Transportation on Environment: A Spatial Approach. Desalination, 226, 279-288. 
https://doi.org/10.1016/j.desal.2007.02.111

FAO (2010). FAO Land Tenure Studies: Compulsory Acquisition of Land and Compensation. Rome.

Gichaga, F. J. (2017). The Impact of Road Improvements on Road Safety and Related Characteristics. IA TSS Research, 40, 72-75. https://doi.org/10.1016/j.iatssr.2016.05.002

Law Library of Congress (2014). National Funding of Road Infrastructure: Comparative Summary. Washington DC: Global Legal Research Centre.

Meik, J. M., Jeo, J. R., Mendelsohn III, K. E., \& Jenks, K. E. (2002). Effects of Bush Encroachment on an Assemblage of Diurnal Lizard Species in Central Namibia. Biological Conservation, 106, 29-36. https://doi.org/10.1016/S0006-3207(01)00226-9

Ministry of Environment and Tourism (2014). Environmental Impact Assessment. Windhoek.

Ovubude, N. N. (2005). The Role of Transport in Rural Development: A Case Study of Badagry Local Government Area of Lagos State. Unpublished M.Sc. Thesis, Centre for Transport Studies.

Petzman (2009). The Effects of Automobile Safety Regulation. Journal of Political Economy, 83-84, 677-725. https://doi.org/10.1086/260352

Ritz, H., \& Clarke, C. (2010). Population Dynamics, the Environment and Demand for Water and Energy in Namibia (37 p.). DEA Research Discussion Paper 7.

Rodrigue, J. P. (2012). The Geography of Transport Systems. New York: Routledge. https://doi.org/10.4324/9780203371183

Santos, G. (2017). Road Transport and $\mathrm{CO}_{2}$ Emission: What Are the Challenges? Transport Policy, 59, 71-74. https://doi.org/10.1016/j.tranpol.2017.06.007

Soehodho, S. (2016). Public Transportation Development and Traffic Accident Prevention in Indonesia. IATSS Research, 40, 76-80. https://doi.org/10.1016/j.iatssr.2016.05.001

Starkey, P., Ellis, S., Hine, J., \& Ternell, A. (2012). Improving Rural Mobility: Options for Developing Motorized and Nonmotorized Transport in Rural Areas. World Bank Technical Paper No. 525.

Wegman, F. (2017). The Future of Road Safety: A World Perspective. IATSS Research, 40, 66-71. https://doi.org/10.1016/j.iatssr.2016.05.003

Welman, J., \& Kruger, S. (2001). Research Methodology for the Business and Administrative Sciences. Cape Town: Oxford Press. 